\title{
Editorial
}

\section{Power, Discourse and Resistance in Mental Health Care.}

\author{
Dave Holmes \& Amélie Perron \\ School of Nursing, University of Ottawa
}

Cite as: Holmes, D. \& Perron, A. (2020). Power, Discourse and Resistance in Mental Health Care. Witness: The Canadian Journal of Critical Nursing Discourse, Vol 2(2), pp 1-2. https//:doi.org/10.25071/22915796.85

We are both delighted to introduce this special issue of Witness: The Canadian Journal of Critical Nursing Discourse exploring some of the ways that current discourses in mental health care can produce and reinforce precarious mental health conditions, including emotional distress, that create damaging subjectivities for those who are trapped one way or the other in the psychiatric apparatus. The lived-experience of patients is often characterized by traumatic experience even within our healthcare system, leading to exacerbated psychological difficulties, stigmatization, marginalization, exclusion and various forms of violence. The papers included in this special issue seek to make visible alternative and critical discourses (and practices) that challenge harmful processes.

This special issue of Witness aims to foster and bring together critical perspectives on mental healthcare matters that directly relate to contemporary notions of mental health and mental illness. It seeks to promote critical nursing scholarship that brings forth the complex intersections of sex, gender, race, class, age and ability and their effects on persons' capacity to conform to social expectations, including those held by health professionals. Such expectations are neither neutral nor inconsequential. For many individuals, groups and communities, they predetermine discourses of normality, acceptance and inclusion on the one hand, and of abnormality, rejection and exclusion on the other. They also crystallize corresponding (frailed, failed) identities in ways that both open up and close off opportunities for representation, recognition, justice and equity.

We believe that making sense of the above is key to understanding two distinct but interrelated phenomena: the growing pathologization of human thoughts, emotions and behaviours, and the parallel downplaying of systems (including the healthcare system) of discrimination and oppression that undermine human agency, personhood and connectedness, leaving only individual explanations of mental distress centered around 'deficits'. The language of mental health and illness suffuses everyday life in such a way that every emotion brought on by the struggles or pleasures of life can become a symptom to be clinically captured, governed and treated. In short, we are all subjugated to an expert evaluation of whether our thinking, desires and functioning fall within social expectations and norms. This penetrating clinical gaze ends up determining the way we perceive ourselves, our capacities and decisions, how we resolve problems, and how we categorize our responses to everyday occurrences. It also changes the way we perceive others around us, in particular those who think and act outside the realm of what has been constructed as 'normal'. Yet 'normal' is a moving target, spurred by multiple forces that both converge and diverge, including free-market policies, the medico-industrial complex, recovery models of care, neurobiological 'discoveries' and human rights discourses. Defining 'normal' is therefore a powerful and exclusionary act that must be critically examined and challenged with alternative social, economic, scientific and legal counter-narratives. 
There is a pressing need to question those discourses, practices, institutions and laws that shape the realities of persons who experience emotional difficulties and/or who are constructed as mentally ill. We believe there is also a need to challenge and rethink the way certain state agents, such as nurses, are called upon to intervene on those individuals deemed to pose a problem because of their mental state. Nurses practice at the intersection of individual and collective experiences, state objectives, clinical guidelines and scientific evidence. They play a key role in the way current configurations of care and support can perpetuate or disrupt patterns of suffering, exclusion and violence. In other words, they are unequivocally bound to people's experiences of mental health and illness. Nursing scholarship in this area is thus critical in order to shape a healthcare agenda that is respectful of people's agency and personhood. We believe this special issue will contribute meaningfully and decisively to the discussion, toward the full realization of social justice, equity and human dignity in mental health work.

This special issue begins with a paper providing a critical analysis of the judiciarization process of persons diagnosed as mentally ill and its impact on nursing practice. In order to explore this phenomenon, Paradis-Gagné and co-authors employed a Foucauldian discourse analysis. The result of this analysis fosters our reflection on the experiences and practices that take place at the psychiatric and judicial interface. Paradis-Gagné and colleagues purport that by acting in seemingly humanistic and therapeutic roles, nurses are simultaneously and inevitably fulfilling a mandate of social control which, to date, remains relatively under documented.

This first paper is followed by Michelle Danda's critical piece regarding chemical restraints. Her empirical research explored mental health nurses' experience of the use of chemical restraint in times of 'behavioural emergency.' Eight adult acute inpatient mental health nurses were interviewed using a phenomenological approach. This critical analysis explores the complex clinical and ethical decision-making aspects involved in mental health nurses' use of this coercive intervention.

Danda authors another key paper in which she explores an emerging research methodology called "duoethnography". She proposes this approach as an avenue to revive mental health nursing by subverting the dominant postpositivist, scientifically driven, medically framed and reductionist evidence-based practice perspective, in order to gain greater understanding of the nuances of mental health nursing practice. According to Danda, duoethnography offers promise in challenging nursing research norms embedded in an empirically based medical model.

Finally, this special edition of Witness closes with an article in French written by Kaszap and Holmes. Their paper reports the results of a critical ethnographic research looking at sexuality amongst male patients hospitalized in a Canadian maximum security forensic psychiatric facility. Results show that patients' sexual health is impaired by the lack of clear institutional policies, health professionals' personal values and finally by patients' fear of retaliation.

We hope you will enjoy this special issue of Witness as much as we have enjoyed putting it together with the precious help of Editor-in-Chief Dr Cheryl L van Daalen-Smith.

\author{
Dave Holmes, PhD, RN, FAAN \\ Professor and University Research Chair \\ University of Ottawa, School of Nursing \\ Email:dholmes@uottawa.ca
}

Amélie Perron, $\mathrm{PhD}, \mathrm{RN}$

Associate Professor

University of Ottawa, School of Nursing

Email: Amelie.Perron@uottawa.ca 